\title{
Adventitious root formation in olive (Olea europaea L.) microshoots: anatomical evaluation and associated biochemical changes in peroxidase and polyphenol oxidase activities
}

\author{
By E. MACEDO ${ }^{1}$, C. VIEIRA ${ }^{1}$, D. CARRIZO ${ }^{1}$, S. PORFIRIO ${ }^{1}$, H. HEGEWALD $^{1}$, \\ B. ARNHOLDT-SCHMITT ${ }^{2}$, M. L. CALADO ${ }^{3}$ and A. PEIXE ${ }^{1 *}$ \\ ${ }^{1}$ Laboratory of Biotechnology and Plant Breeding, ICAAM, University of Évora, Ap. 94, \\ 7002-554 Évora, Portugal \\ ${ }^{2}$ Laboratory of Plant Molecular Biology, EU Marie Curie Chair, ICAAM, University of Évora, \\ Ap. 94, 7002-554 Évora, Portugal \\ ${ }^{3}$ Unit of Genetic Resources, Eco-Physiology and Plant Breeding, INRB, Estrada Gil Vaz, \\ 7350-228 Elvas, Portugal
}

(e-mail: apeixe@uevora.pt)

(Accepted 18 September 2012)

\section{SUMMARY}

Trials were performed using in vitro-cultured microshoots of the olive (Olea europaea L.) cultivar 'Galega vulgar', as initial explants, to identify histological events and modifications in peroxidase and polyphenol oxidase activities during adventitious root formation. Explant bases were submitted to a $10 \mathrm{~s}$ quick-dip treatment to promote rooting, using a sterile solution of $14.7 \mathrm{mM}$ indole-3-butyric acid (IBA). Samples for histology and quantification of enzyme activities were collected at pre-established periods from 0 to $720 \mathrm{~h}$. The first signs of modifications in stem cell morphology were observed $96 \mathrm{~h}$ after explant inoculation on olive culture medium (OM), with some cortical cells showing a dense cytoplasm and a large central nucleus, with visible nucleoli. The first mitotic events were observed after $144 \mathrm{~h}$ and evolved via two different pathways: non-specific cell division, leading to callus formation; and organised cell division, leading to the formation of root meristemoids. After $456 \mathrm{~h}$, the first organised root primordia became visible. No root formation was achieved without earlier callus development, and $89 \%$ of root primordia originated from tissues other than cambial/phloem tissue. Peroxidase and polyphenol oxidase activities were recorded throughout the whole rooting process. The first significant modification in enzyme activity, with a drop from 0.19 to $0.14 \Delta \mathrm{A}_{490} \mathrm{units} \mathrm{min}^{-1} 50 \mathrm{mg}^{-1}$ of explant material, was observed for peroxidase within the first $4 \mathrm{~h}$ after IBA treatment. Subsequent changes in both enzyme activities could be correlated with different phases of the adventitious rooting process.

$\mathbf{C}$ onsiderable progress has been made in the last $20-$ 30 years towards understanding rooting by characterising it as an evolutionary process consisting of a successive series of interdependent phases (i.e., induction, initiation, and expression), each having specific physiological and environmental requirements (Moncousin et al., 1988; Gaspar et al., 1992; Rout et al., 2000).

Adventitious roots originate via the redifferentiation of several cell types such as those from sub-epidermal tissues, the cortex, cambium, secondary phloem, pericycle, or vascular bundles. In olive, the capacity to develop adventitious roots has proved to be extremely variable among cultivars (Salama et al., 1987; El-Said et al., 1990; Fouad et al., 1990). Differences in the anatomical structure of cuttings were proposed to explain this dependence on genotype, with several authors stating that the presence of a continuous ring of sclerenchyma, between the phloem and the cortex, may act as a mechanical barrier to root emergence (Salama et al., 1987; Qrunfleh et al., 1994). Nevertheless, other reports have provided evidence that the difficulty in rooting olive cuttings could not be correlated with the

*Author for correspondence. anatomical structure of the cutting, and that genetic, biochemical, or physiological causes, rather than anatomical ones, could be related to the incapacity of several olive cultivars to form adventitious roots (Bakr et al., 1977; Fabbri, 1980).

Several studies on adventitious root formation have highlighted the important role that oxidative enzymes such as peroxidases (POX) and polyphenol oxidases (PPO) play in this process (Moncousin and Gaspar, 1983; Berthon et al., 1989; Gaspar et al., 1992; Rival et al., 1997; Rout et al., 1999; Cheniany et al., 2010; Fu et al., 2011).

Plant peroxidases (POX; E.C. 1.11.1.7) are haemcontaining enzymes that catalyse the oxidation of a diverse group of organic compounds. Studies on adventitious root formation have shown that POX isoenzymes play a fundamental role in the rooting of cuttings, with changes in POX activity often being used as a biochemical marker for the rooting process (Gaspar et al., 1992; Metaxas et al., 2004; Syros et al., 2004; Hatzilazarou et al., 2006).

Typically, the minimum POX activity appears at the root induction phase, while a subsequent increase, reaching a peak of activity, marks the end of root initiation and the start of the root development phase (Gaspar et al., 1992). Chao et al. (2001) reported that a 